\title{
Social Media and Loneliness
}

\author{
Abby Halston ${ }^{1}$, Darren Iwamoto ${ }^{1}$, Michael Junker ${ }^{1} \&$ Hans Chun ${ }^{1}$ \\ ${ }^{1}$ School of Education and Behavioral Sciences, Chaminade University, Honolulu, United States \\ Correspondence: Darren Iwamoto, School of Education and Behavioral Sciences, Chaminade University, \\ Honolulu, HI., 96816, United States. E-mail: diwamoto@chaminade.edu
}

Received: June 14, 2019

doi:10.5539/ijps.v11n3p27
Accepted: July 11, 2019

Online Published: July 13, 2019

URL: https://doi.org/10.5539/ijps.v11n3p27

\begin{abstract}
Particularly to the younger Millennials and Generation Z, it appears as if social networking sites (SNS) is coming to the point of replacing normal social interactions and removing much of the personal aspects out of socialization. With the Internet literally being able to move at the speed of light, face-to-face interactions appear to be slowly in decline. As a highly social species, humans require interaction to maintain a healthy psychological state. This research has been conducted to analyze the level of loneliness and the level of SNS use with the intent of reinvestigating previous research on the correlations of SNS and loneliness with a more diverse demographic sample. In addition, this study has been designed to see if high usage of specific platforms has an increased likelihood to be related with loneliness. This research has been conducted by means of an anonymous survey of college students at a university in the Pacific to determine the amount of time spent on SNS, activities conducted while utilizing SNS, the priorities placed, and other information in regards to SNS usage. Inquiry was also conducted in analyzing how interpersonal relationships are related to or affected by SNS. This has been combined with the revised UCLA loneliness scale to determine if there is a correlation between SNS use, specific platform use, and loneliness. While previous similar studies have been conducted, the two primary differences are the diversity in the demographics available to be surveyed and the attempt at identifying if a specific platform is more likely to be related with loneliness.
\end{abstract}

Keywords: social media, loneliness, social connectedness

\section{Introduction}

The concept of socialization is a foundational aspect of humans as a species. It is an innate desire to congregate, gather, share information and resources. Whatever means necessary, humans have strived to build, maintain and sculpt their social networks. In previous generations, socialization and social connectedness occurred through religious gatherings, galas, formal balls, and other types of social gatherings. Prior to technological advances, our ancestors used animals, like pigeons, to transport letters to one another. People would ride horseback for days to deliver messages to others. As technology improved, a new revolution of community occurred. First, it was the telegraph in 1837, which could perform the duties of the postal service at a much faster manner. The issue was that it was encoded; not everyone could dedicate the time and effort into learning to speak "telegraph." As humans are determined to make life as convenient and simple as possible, an alternative was created, complex in its makings, but simple in its use: the telephone. When the telephone was invented in 1876, it revolutionized long-distance communication more than the telegraph did, and soon it was commonplace to use such methods to communicate to social networks regardless of the distance. With this in mind, it comes as little surprise that when the Advanced Research Projects Agency created the ARPAnet in 1969 for the military, it too would be utilized for social purposes.

As early as 1988, IRC, or Internet relay chat, has been used for social interactions (Werry, 1996). You could find someone with a computer, anywhere with connection, and have a live chat. It allowed for second-by-second communication through virtual interactions. So what comes next? The next step was to create more "lifelike" interactions. Thus became the advent of profile based online socialization, known as Social Networking Sites (SNS), but most commonly known as Social Media.

Before Facebook, there was what can be considered the forbearer of modern SNS. It was called Sixdegrees. Founded in 1997, seven years before Facebook, this little known SNS had its own profile-building, friends listing, and even friends-of-friends capabilities (Keitzmann, Hermkens, McCarthy \& Silvestre, 2011). This 
opened the door for other companies to make their attempts at online social networking. Sites like Myspace, Indeed, and YouTube all came out in the years following the decline of Sixdegrees. Shortly after, Facebook appeared, quickly dominating the other SNS. By 2009, only three years after the inventions of Facebook, it had become the largest SNS in the world (Press, 2018). By this time, SNS had become a staple of the generation.

With the common use of SNS by a wide variety of people, it started to progress beyond its intended social uses. Reports of what is now called cyberbullying came forward, of Internet addictions and other mental health concerns. The first hint of this was with the suicide of Ryan Halligan, age 13, who was aggressively bullied through the AOL instant messaging service ("Ryan's Story," 2003). After this, the psychological effects of the Internet became a source of interest for both the public and researchers.

SNS became a topic of a different type of interest, with its millions of users connecting across the globe (Boyd \& Ellison, 2007). Research began inquiring about the psychological effects of SNS upon users and how it affects day-to-day life. The 2017 Pediatric Academic Societies Meeting reported that admissions of suicidal teenagers to hospitals had tripled since 2004 , which a frightening $26 \%$ of parents in the U.S. reporting that their children have experienced cyberbullying (Cook, 2018).

With fairly extensive research having been conducted on the effects of SNS and loneliness, this research will be targeting a more diverse demographic than in previous studies to determine a correlation between specific SNS platforms (ie. Twitter, Facebook, Instagram, etc.) to see if a specific SNS platform has a higher relation with loneliness than others.

\subsection{Types of Users}

There are generally considered to be three types of users identified, passive, active, and broadcasting (Burke, Marlow \& Lento, 2010). These two categories encompass the basics of user dynamics. Active users, also called interactive users, predominantly utilize SNS for messaging, posting updates and photos, and similar activities that involve nurturing an existing social network and creating a new one (Deters \& Mehl, 2013). Liking, commenting, tagging, posting to someone's "wall" and direct messaging all fall under this category.

Passive users, sometimes known as passive follower or content consumer, utilize SNS for observance rather than interaction, mainly checking the news feed and similar passive viewing (Krasnova, Wenninger, Widjaja \& Buxmann, 2013). The viewing of news, postings, pictures, and updates without "liking" or "commenting" are the key components of a passive user (Burke, Kraut \& Marlow, 2011). An extreme form of passive usage is "Facebook Stalking" (Yang \& Brown, 2013), in which an individual often searches through the entire history of another user.

The last major group of users are called broadcasters. Broadcasters utilize SNS to project themselves to others without direction. This type of user does not specifically direct their postings to another user, rather it is intended to be consumed by a wider range of users (Burke et al., 2011). It is often used for elevating one's standing in the respective social group or to set the broadcaster apart from the masses.

The importance of understanding user types is that research has shown that passive users experience loneliness at a higher level than active users (Burke et al., 2010) and have increased feelings of envy (Krasnova et al., 2013) which has a direct intertwining with loneliness and low self-esteem.

\subsection{SNS Platforms}

Different SNS platforms have different user purposes. Created in March of 2006, Twitter is a microblogging service that allows users to post "tweets" that are 140 characters long about any topic of their choice (Kwak, Lee, Park \& Moon, 2010). According to Internet Live Stats ("Twitter usage," 2018), a website that collects data on various Internet usage, Twitter produces on average over 500 million "tweets" per day on thousands of different topics. It is a popular source of "quick news," with most major news stations, media, and public officials posting sometimes daily on their accounts. The majority spend time posting about themselves, spending more time posting about their lives and activities and less time responding to individualized messages. Another major use is viewing other's posts, celebrity "tweets" and news clips (Naaman, Boase, \& Lai, 2010), which adheres to the passive user and "broadcaster" categories.

Facebook, on the other hand, has a significantly larger user type, encompassing all three categories extensively (Burke et al., 2011). Facebook, founded in 2004, became the largest SNS in existence. With Facebook, a user can post on their "wall," on their friends' "wall," post pictures, direct message other users, "like" people's posts, and even go shopping. The Facebook "news feed" is where posts from other people will populate, as well as the posts of accounts that are "followed," such as popular celebrities, news, and entertainment. In a survey conducted in Canada, $71 \%$ of the participants stated that their primary reason for Facebook was to "keep up with 
the news" (Fletcher, Hermida, Korell \& Loga, 2012). Facebook has also been shown to be correlated both with increased psychological well-being and increased loneliness, depending on the type of usage (Burke et al., 2010).

In contrast with other SNS, Pinterest is a nearly exclusively passive SNS. Pinterest, along with Etsy, Deviantart, and other websites, is known as a social curation site. While considered an SNS, it has a significantly different purpose. Users will create "boards" to which most users simply "pin" pictures that they like to their account, using homophily to determine what to add to an existing theme (Chang, Kumar, Gilbert \& Terveen, 2014). Multiple boards can exist, with multiple themes. The "home" screen is where "pins" populate via an algorithm known as "guided search," which means similar images to what has been consistently viewed, searched and "pinned" appear. Most of the users on this type of social curation site are highly passive, rarely leaving comments, direct messaging or contacting other users.

Snapchat, which is a time-limited messaging service, has now grown more popular than Facebook in the younger demographics (Pewik \& Joinson, 2016), making it of importance to study. It is a form of direct messaging and instant messaging, using pictures and videos to communicate along with actual messaging and "text" written on the picture or video itself. The unique aspect is that it is time-limited. The user may choose how long the image displays itself when sent, and after opened, the recipient may only look at it once more before the image or video expires. This is also the same for the written messages. As soon as the message screen is exited, all texts is removed if it is not saved. It is popular with the younger demographic due to its "filters" where the user can take pictures of themselves and have various features superimposed along with the image, including voice changing capabilities. The primary user type of Snapchat is interactive, which falls under as a subcategory of active users. It is of increased interest as research has shown that Snapchat is the largest SNS cause of envy, surpassing Facebook (Khalid, Muscanell \& Utz, 2015) which has been shown to correlate to loneliness (Krasnova et al., 2013).

While oftentimes not considered to be an SNS, YouTube is a firmly established form of social networking and will be considered as such in this research. With its extensive variety of videos, it is considered to be the most used SNS, despite not having as many user accounts (Lange, 2008). Those with user accounts, which are called "channels," and those without alike are able to access the wide variety of videos ranging from music to cinematic trailers, animated entertainment to education, news and more. While having a decent quantity of passive, active and broadcasting users, the majority are passive viewers, though it may be quantified differently as the nature of the SNS allows for comments but does not usually warrant a response from the "channel" owner.

\subsection{SNS Usage and Loneliness}

This leads to the first research question. Question 1: is there a specific platform(s) that is correlated with loneliness? To determine this, each survey came with a series of questions pertaining to different platforms. Questions about the number of accounts per platform, hours spent on each platform, and in which order the participant typically checks each SNS platform were included. This, along with the data collected using the revised UCLA loneliness scale will statistically show if there is a correlation between increased hours, the priority of multiple accounts on a specific SNS platform, and the level of participant's perceived loneliness. With the research by Burke et al. (2010) on Facebook and envy and how envy is correlated to loneliness and the newer research by Khalid et al. (2015) on how Snapchat is now the largest source of online envy, our first hypothesis is H1: Snapchat has the highest correlation with loneliness.

The next step was to determine whether the number of hours spent on SNS platforms correlated with loneliness. Question 2: How does the amount of hours on a specific SNS platform affect perceived loneliness? Research states that increased SNS activity, both active and interactive usage, decreased loneliness because it increased the feeling of connectivity (Deters \& Mehl, 2013). Research also shows that passive users have the increased likelihood for increases in loneliness (Burke et al., 2010). Thus, our second hypothesis is H2: Increased passive usage of SNS platforms is correlated with increased loneliness.

The final question we asked is Question 3: Does the nature of the platform increase the likelihood for loneliness? What this is asking is if the design of the platform can affect the type of user, therefore be related to increased loneliness. For example, Snapchat is a highly interactive SNS that relies on time-sensitive direct messaging. Since it is all image-based, there has been shown to be tendencies to utilize this platform, along with Instagram, for self-promotion (Khalid et al., 2015). With increases of jealousy and envy typically comes feelings of self-depreciation and self-doubt, which has often been present with increases in loneliness (Festinger, 1954). Therefore, the final hypothesis is H3: Platforms that encourage passive use and self-promotion are more likely to be related to increased loneliness. 


\section{Method}

In order to discovery correlational data between SNS usage, the amount of usage on each platform, user purpose, and most commonly used platform to determine the effects of both specific websites and SNS as a whole on loneliness, 326 students were surveyed in the fall of 2018. Permission was granted from the university for this research and was IRB approved. The survey contained questions in regards to basic demographic, number of SNS utilized, hours spent on individual SNS, social capital and basic information about content. Based on the research literature, the revised UCLA loneliness scale was chosen as the instrument of quantitative assessment due to the high reliability and validity of assessing relationship between the scores of an individual's high subjective feeling of loneliness, as well as feeling of social isolation. Russell, Peplau and Ferguson (1978) established high internal consistency $(\mathrm{r}=.96)$ and a test-retest correlation over a two month of .73. Russell (1996) also established high internal consistency (coefficient a ranging from .89 to .94 ), and test-retest reliability over 1 -year period $(\mathrm{r}=.73)$ to score the level of loneliness.

\subsection{Participants}

Each participant was given an informed consent form that was signed and returned to the researchers. On the survey, demographic information recorded anonymously. Table 1 indicates the ethnicity of the participants.

Table 1. Ethnicity of the participants

\begin{tabular}{lllll}
\hline Ethnicity & Frequency & Percent & Valid Percent & Cumulative Percent \\
\hline Asian & 124 & 38.9 & 38.2 & 8.2 \\
African American & 6 & 1.8 & 1.8 & 40.0 \\
Hispanic & 21 & 6.4 & 6.5 & 46.5 \\
Two or more & 34 & 10.4 & 10.5 & 56.9 \\
(non-Hawaiian) & & & & \\
Pacific Islander & 67 & 20.6 & 20.6 & 82.8 \\
Caucasian & 56 & 17.2 & 17.2 & 100.0 \\
Valid Total & 325 & 99.7 & 100.0 & \\
Missing & 1 & .3 & & \\
Total & 326 & 100.0 & & \\
\hline
\end{tabular}

The importance of this table is that it demonstrates the wide range of diversity of the participants in this study, lending a significant range of multicultural perspectives and reactions towards SNS and its usage.

Table 2. Gender of the participants

\begin{tabular}{lllll}
\hline Gender & Frequency & Percent & ValidPercent & Cumulative Percent \\
\hline Male & 82 & 25.2 & 25.3 & 25.3 \\
Female & 242 & 74.2 & 74.7 & 100.0 \\
Valid Total & 324 & 99.4 & 100.0 & \\
Missing & 2 & .6 & & \\
Total & 326 & 100.0 & & \\
\hline
\end{tabular}

In previous studies, gender has been noted as an influencing variable in terms of SNS and loneliness. Krasnova et al. (2013) noted in their research that females had a higher tendency for upward comparison, which was correlated to loneliness. This is why gender was a variable considered in this research.

Table 3 represents the age variance of the participants. The age was self-reported with a wide range, from 17 years old up to 69 years. Age is a noteworthy variable to include when analyzing the effects of SNS on loneliness. With increased age and maturity, the negative impacts of SNS should have decreased correspondingly and therefore was included in this study. 
Table 3. Age of the participants

\begin{tabular}{|c|c|c|c|c|}
\hline Age & Frequency & Percent & Valid Percent & Cumulative Percent \\
\hline 2 & 1 & .3 & .3 & .3 \\
\hline 17 & 1 & .3 & .3 & .6 \\
\hline 18 & 70 & 21.5 & 22.2 & 22.9 \\
\hline 19 & 62 & 19.0 & 19.7 & 42.5 \\
\hline 20 & 59 & 18.1 & 18.7 & 61.3 \\
\hline 21 & 52 & 16.0 & 16.5 & 77.8 \\
\hline 22 & 25 & 7.7 & 7.9 & 85.7 \\
\hline 23 & 11 & 3.4 & 3.5 & 89.2 \\
\hline 24 & 10 & 3.1 & 3.2 & 92.4 \\
\hline 25 & 6 & 1.8 & 1.9 & 94.3 \\
\hline 26 & 2 & .6 & .6 & 94.9 \\
\hline 27 & 2 & .6 & .6 & 95.6 \\
\hline 28 & 3 & .9 & 1.0 & 96.5 \\
\hline 29 & 3 & .9 & 1.0 & 97.5 \\
\hline 30 & 1 & .3 & .3 & 97.8 \\
\hline 31 & 2 & .6 & .6 & 98.4 \\
\hline 32 & 1 & .3 & .3 & 98.7 \\
\hline 34 & 1 & .3 & .3 & 99.0 \\
\hline 43 & 1 & .3 & .3 & 99.4 \\
\hline 45 & 1 & .3 & .3 & 99.7 \\
\hline 69 & 1 & .3 & .3 & 100.0 \\
\hline Valid Total & 315 & 96.6 & 100.0 & \\
\hline Missing & 11 & 3.4 & & \\
\hline Total & 326 & 100.0 & & \\
\hline
\end{tabular}

Research found that the usage purpose of SNS platforms changed based upon college classification (ie. freshman, sophomore, junior, senior) and that the number of hours spent, and value gained from SNS decreases as college students proceed in their academic experience (Yang \& Brown, 2013). This research corresponded with all three of the hypotheses, which is why it was included as a variable in this study. 
Table 4. College year classification of the participants

\begin{tabular}{lllll}
\hline Classification & Frequency & Percent & Valid Percent & Cumulative Percent \\
\hline First year/Freshman & 88 & 27.0 & 27.2 & 27.2 \\
Sophomore & 81 & 24.8 & 25.0 & 52.2 \\
Junior & 80 & 24.5 & 24.7 & 76.9 \\
Senior & 71 & 21.8 & 21.9 & 98.8 \\
Unclassified & 2 & .6 & .6 & 99.4 \\
12.00 & 1 & .3 & .3 & 99.7 \\
20.00 & 1 & .3 & .3 & 100.0 \\
Valid Total & 324 & 99.4 & 100.0 & \\
Missing & 2 & .6 & & \\
Total & 326 & 100.0 & & \\
\hline
\end{tabular}

3.2 Procedures and Measures

This research was conducted entirely in-person, with participants physically filling out informed consent forms and paper surveys for data collection. The researchers visited individual classrooms and handed out surveys to the present students. Participants were informed that the survey was voluntary, and the informed consent form was explained. In addition to the survey, the UCLA revised loneliness scale was given to each participant for the purpose of measuring the corresponding loneliness score. The survey and UCLA revised loneliness scale was distributed to students over the course of a semester.

The survey format was 32 questions, with most being numerical fill in the blank (e.g., how many hours a day do you spend on Facebook?). The 20-question UCLA revised loneliness scale was scored on a four-point Likert scale, where 1 corresponds to never and 4 corresponds to often and includes questions in regards to feelings and emotions (e.g.ie, I feel in tune with the people around me; There is no one I can turn to). The UCLA revised loneliness scale also contains inverse questions (question number: 1, 4, 5, 6, 9, 10, 15, 16, 19 and 20), which to calculate the sum the applicable question scores must be inverted (e.g., 1 becomes 4, 2 becomes 3, etc.).

The survey was measured in four categories. The first was background. Background includes demographic data: ethnicity, gender, age, classification, major/minor, and whether or not the participant was a member of an SNS.

The second category was the number of SNS platforms utilized. This includes a number of different SNS platforms and the number of accounts per SNS platform.

The third category was priority and usage of SNS platforms. This includes in which order each applicable SNS was checked, which SNS platform is most utilized for posting, and what type of content is shared on each SNS.

The fourth category is number of hours spent on each SNS. This measures the length of time per day users spend on average browsing, posting and viewing various SNS platforms.

The results of these four categories were then correlated with the corresponding UCLA revised loneliness scale scores.

\section{Results}

The results of this study were surprising and contrary to our earlier hypotheses. Much of the previous research indicated a significant correlation between SNS and loneliness. However, our research found minimal correlation between SNS and the UCLA revised loneliness scale score. The only three correlations proved to be significant, the relation between loneliness and which platform that is checked first (Table 5), loneliness and the number of hours spent on Pinterest (Table 11), and loneliness and being befriended by parent (Table 17). 
Table 5. Correlational table of preferred platform check and the level of loneliness

\begin{tabular}{lllllll}
\hline Variable & $\begin{array}{l}\text { Pearson } \\
\text { Correlation }\end{array}$ & Sig. (2-tailed) & $\mathrm{N}$ & $\begin{array}{l}\text { Pearson } \\
\text { Correlation }\end{array}$ & $\begin{array}{l}\text { Sig. } \\
(2 \text {-tailed) }\end{array}$ & $\mathrm{N}$ \\
\hline CO Twitter & 1 & - & 293 & .127 & $.035^{*}$ & 278 \\
Lonesum & .127 & $.035^{*}$ & 278 & 1 & - & 307 \\
\hline
\end{tabular}

Note: *significant at the .05 level.

Table 5 Shows that there is a significant correlation between the checking order of Twitter and loneliness. While not a largely significant at $(\mathrm{r}=.035)$, it is still worth noting. This is in line with our $\mathrm{H} 2$ and $\mathrm{H} 3$.

Table 6. Correlational table of preferred platform check and the level of loneliness

\begin{tabular}{lllllll}
\hline Variable & $\begin{array}{l}\text { Pearson } \\
\text { Correlation }\end{array}$ & Sig. (2-tailed) & $\mathrm{N}$ & $\begin{array}{l}\text { Pearson } \\
\text { Correlation }\end{array}$ & $\begin{array}{l}\text { Sig. } \\
(2 \text {-tailed) }\end{array}$ & $\mathrm{N}$ \\
\hline CO Facebook & 1 & - & 232 & -.013 & .844 & 220 \\
Lonesum & -.013 & .844 & 220 & 1 & - & 307 \\
\hline
\end{tabular}

Note: *significant at the .05 level.

Although Burke et al, (2010) and Krasnova et al. (2013) found that there were significant correlations between SNS and loneliness, this research did not show any significant correlations between the preferred order in checking platforms and loneliness.

Table 7. Correlational table of preferred platform check and the level of loneliness

\begin{tabular}{lllllll}
\hline Variable & $\begin{array}{l}\text { Pearson } \\
\text { Correlation }\end{array}$ & Sig. (2-tailed) & $\mathrm{N}$ & $\begin{array}{l}\text { Pearson } \\
\text { Correlation }\end{array}$ & $\begin{array}{l}\text { Sig. } \\
(2 \text {-tailed) }\end{array}$ & $\mathrm{N}$ \\
\hline CO Youtube & 1 & - & 197 & -.027 & .714 & 278 \\
Lonesum & -.027 & .714 & 187 & 1 & - & 307 \\
\hline
\end{tabular}

Note: *significant at the .05 level.

Although Burke et al, (2010) and Krasnova et al. (2013) found that there were significant correlations between SNS and loneliness, this research did not show any significant correlations between the preferred order in checking platforms and loneliness.

Table 8. Correlational table of preferred platform check and the level of loneliness

\begin{tabular}{lllllll}
\hline Variable & $\begin{array}{l}\text { Pearson } \\
\text { Correlation }\end{array}$ & Sig. (2-tailed) & $\mathrm{N}$ & $\begin{array}{l}\text { Pearson } \\
\text { Correlation }\end{array}$ & $\begin{array}{l}\text { Sig. } \\
(2 \text {-tailed) }\end{array}$ & $\mathrm{N}$ \\
\hline CO Instagram & 1 & - & 130 & -.11 & .899 & 126 \\
Lonesum & -.11 & .899 & 126 & 1 & - & 307 \\
\hline
\end{tabular}

Note: *significant at the .05 level.

Although Burke et al, (2010) and Krasnova et al. (2013) found that there were significant correlations between SNS and loneliness, this research did not show any significant correlations between the preferred order in checking platforms and loneliness.

Table 9. Correlational table of preferred platform check and the level of loneliness

\begin{tabular}{lllllll}
\hline Variable & $\begin{array}{l}\text { Pearson } \\
\text { Correlation }\end{array}$ & Sig. (2-tailed) & $\mathrm{N}$ & $\begin{array}{l}\text { Pearson } \\
\text { Correlation }\end{array}$ & $\begin{array}{l}\text { Sig. } \\
(2 \text {-tailed) }\end{array}$ & $\mathrm{N}$ \\
\hline CO Pinterest & 1 & - & 246 & -.007 & .918 & 234 \\
Lonesum & -.007 & .918 & 234 & 1 & - & 307 \\
\hline
\end{tabular}

Note: *significant at the .05 level.

Although Burke et al, (2010) and Krasnova et al. (2013) found that there were significant correlations between SNS and loneliness, this research did not show any significant correlations between the preferred order in checking platforms and loneliness. 
Table 10. Correlational table of preferred platform check and the level of loneliness

\begin{tabular}{lllllll}
\hline Variable & $\begin{array}{l}\text { Pearson } \\
\text { Correlation }\end{array}$ & Sig. (2-tailed) & $\mathrm{N}$ & $\begin{array}{l}\text { Pearson } \\
\text { Correlation }\end{array}$ & $\begin{array}{l}\text { Sig. } \\
(2 \text {-tailed) }\end{array}$ & $\mathrm{N}$ \\
\hline CO Snapchat & 1 & - & 227 & .081 & .189 & 262 \\
Lonesum & .081 & .189 & 262 & 1 & - & 307 \\
\hline
\end{tabular}

Note: *significant at the .05 level.

Although Burke et al, (2010) and Krasnova et al. (2013) found that there were significant correlations between SNS and loneliness, this research did not show any significant correlations between the preferred order in checking platforms and loneliness.

The next significant correlation was more surprising. Table 11 shows the correlation between hours spent on Pinterest and loneliness.

Table 11. Correlational table of number of hours spent on a platform and loneliness

\begin{tabular}{lllllll}
\hline Variable & $\begin{array}{l}\text { Pearson } \\
\text { Correlation }\end{array}$ & Sig. (2-tailed) & $\mathrm{N}$ & $\begin{array}{l}\text { Pearson } \\
\text { Correlation }\end{array}$ & $\begin{array}{l}\text { Sig. } \\
(2 \text {-tailed) }\end{array}$ & $\mathrm{N}$ \\
\hline $\begin{array}{l}\text { Pinterest } \\
\text { hours }\end{array}$ & 1 & - & 102 & -.212 & $.037^{*}$ & 97 \\
\begin{tabular}{l} 
Lonesum \\
\hline
\end{tabular} & -.212 & $.037^{*}$ & 97 & 1 & - & 307 \\
\hline
\end{tabular}

Note: *significant at the .05 level.

What is interesting about this table is that it contradicts our previous hypotheses regarding the correlation of increased loneliness with increased SNS usage. Table 11 shows that there a negative correlation $(\mathrm{r}=-.212)$ between increased hours spent on Pinterest and loneliness, meaning that rather than the previously assumed increase in loneliness score, increased usage on Pinterest related to a decrease in the loneliness corresponding scores. Again, the significance is small, but is deviant from our initial hypothesis. A possible theory in explanation is based in the nature and purpose of Pinterest. Unlike most of the other popular SNS platforms, Pinterest does not revolve around social networking. Rather, Pinterest is a social curation site (SCS), which is utilized to outline themes and ideas. Pinterest "boards" are consisted of "pins" created and shared by other users to fit the theme of the "board." With minimal interactive features aside from the basic message and "sharing" systems, Pinterest is a predominantly single person SNS.

Another brief theory is that the content of the "pins" revolves around the desires of the user, with the algorithm used by the site "predicting" what the user is most likely going to find appealing by showing similar "pins" to ones that have been previously searched, "pinned" and share. As such, Pinterest may foster positive emotions such as feelings of home, creativity, and art, rather than the negative emotions that are commonly correlated to traditional SNS platforms. Further research will need to be conducted to validate whether or not the negative correlation between loneliness score and hours spent on Pinterest continues to be present.

Similarly to the results of preferred order in checking platforms, the hours spent on each platform was also contrary to the original hypotheses.

Table 12. Correlational table of number of hours spent on a platform and loneliness

\begin{tabular}{lllllll}
\hline Variable & $\begin{array}{l}\text { Pearson } \\
\text { Correlation }\end{array}$ & Sig. (2-tailed) & $\mathrm{N}$ & $\begin{array}{l}\text { Pearson } \\
\text { Correlation }\end{array}$ & $\begin{array}{l}\text { Sig. } \\
(2 \text {-tailed) }\end{array}$ & $\mathrm{N}$ \\
\hline $\begin{array}{l}\text { Facebook } \\
\text { hours }\end{array}$ & 1 & - & 222 & -.016 & .812 & 210 \\
Lonesum & -.016 & .812 & 210 & 1 & - & 307 \\
\hline
\end{tabular}

Note: *significant at the .05 level.

As before, Burke et al, (2010) and Krasnova et al. (2013) found that there were significant correlations between SNS and loneliness. However, this research has not shown any significant correlations between hours spent on SNS platforms and loneliness. 
Table 13. Correlational table of number of hours spent on a platform and loneliness

\begin{tabular}{lllllll}
\hline Variable & $\begin{array}{l}\text { Pearson } \\
\text { Correlation }\end{array}$ & Sig. (2-tailed) & $\mathrm{N}$ & $\begin{array}{l}\text { Pearson } \\
\text { Correlation }\end{array}$ & $\begin{array}{l}\text { Sig. } \\
(2 \text {-tailed) }\end{array}$ & $\mathrm{N}$ \\
\hline $\begin{array}{l}\text { Instagram } \\
\text { hours }\end{array}$ & 1 & - & 290 & .045 & .416 & 274 \\
Lonesum & .045 & .461 & 274 & 1 & - & 307 \\
\hline
\end{tabular}

Note: *significant at the .05 level.

As before, Burke et al, (2010) and Krasnova et al. (2013) found that there were significant correlations between SNS and loneliness. However, this research has not shown any significant correlations between hours spent on SNS platforms and loneliness.

Table 14. Correlational table of number of hours spent on a platform and loneliness

\begin{tabular}{lllllll}
\hline Variable & $\begin{array}{l}\text { Pearson } \\
\text { Correlation }\end{array}$ & Sig. (2-tailed) & $\mathrm{N}$ & $\begin{array}{l}\text { Pearson } \\
\text { Correlation }\end{array}$ & $\begin{array}{l}\text { Sig. } \\
(2 \text {-tailed) }\end{array}$ & $\mathrm{N}$ \\
\hline Twitter hours & 1 & - & 183 & .120 & .116 & 173 \\
Lonesum & .120 & .116 & 173 & 1 & - & 307 \\
\hline
\end{tabular}

Note: *significant at the .05 level.

As before, Burke et al, (2010) and Krasnova et al. (2013) found that there were significant correlations between SNS and loneliness. However, this research has not shown any significant correlations between hours spent on SNS platforms and loneliness.

Table 15. Correlational table of number of hours spent on a platform and loneliness

\begin{tabular}{lllllll}
\hline Variable & $\begin{array}{l}\text { Pearson } \\
\text { Correlation }\end{array}$ & Sig. (2-tailed) & $\mathrm{N}$ & $\begin{array}{l}\text { Pearson } \\
\text { Correlation }\end{array}$ & $\begin{array}{l}\text { Sig. } \\
(2 \text {-tailed) }\end{array}$ & $\mathrm{N}$ \\
\hline Youtube hours & 1 & - & 239 & .103 & .120 & 229 \\
Lonesum & .103 & .120 & 229 & 1 & - & 307 \\
\hline
\end{tabular}

Note: *significant at the .05 level.

As before, Burke et al, (2010) and Krasnova et al. (2013) found that there were significant correlations between SNS and loneliness. However, this research has not shown any significant correlations between hours spent on SNS platforms and loneliness.

Table 16. Correlational table of number of hours spent on a platform and loneliness

\begin{tabular}{lllllll}
\hline Variable & $\begin{array}{l}\text { Pearson } \\
\text { Correlation }\end{array}$ & Sig. (2-tailed) & $\mathrm{N}$ & $\begin{array}{l}\text { Pearson } \\
\text { Correlation }\end{array}$ & $\begin{array}{l}\text { Sig. } \\
(2 \text {-tailed) }\end{array}$ & $\mathrm{N}$ \\
\hline $\begin{array}{l}\text { Snapchat } \\
\text { hours }\end{array}$ & 1 & - & 267 & .034 & .595 & 254 \\
\begin{tabular}{l} 
Lonesum \\
\hline
\end{tabular} & .034 & .595 & 254 & 1 & - & 307 \\
\hline
\end{tabular}

Note: *significant at the .05 level.

As before, Burke et al, (2010) and Krasnova et al. (2013) found that there were significant correlations between SNS and loneliness. However, this research has not shown any significant correlations between hours spent on SNS platforms and loneliness.

While most of this data was in contradiction of preexisting research as well as the hypothesis proposed in this paper, the correlation between type of friend request, specifically a friend request from a parent, and loneliness was shown to be a significant correlation. 
Table 17. Correlational table of type of friend requests and loneliness

\begin{tabular}{lllllll}
\hline Variable & $\begin{array}{l}\text { Pearson } \\
\text { Correlation }\end{array}$ & Sig. (2-tailed) & $\mathrm{N}$ & $\begin{array}{l}\text { Pearson } \\
\text { Correlation }\end{array}$ & $\begin{array}{l}\text { Sig. } \\
(2 \text {-tailed) }\end{array}$ & $\mathrm{N}$ \\
\hline $\begin{array}{l}\text { Parent } \\
\text { befriending }\end{array}$ & 1 & - & 257 & .172 & $.007^{*}$ & 245 \\
\begin{tabular}{l} 
Lonesum \\
\hline
\end{tabular} & .172 & $.007^{*}$ & 245 & 1 & - & 307 \\
\hline
\end{tabular}

Note: *significant at the .05 level.

A possible reason for this may lie in parental factors, such as an overprotective parent hampering social abilities, thus increasing loneliness as a byproduct. In addition to this, while still falling under overprotective and overbearing parents, a possible theory is that the parent attempts to constantly monitor their child which could stifle the child's personal desires and social interactions, thus leading to loneliness. A third theory that was considered was pre-existing history of mental or physical health issues, such as social anxiety or depression, which both correlate to loneliness. This theory postulates that the loneliness is a byproduct of an external factor and the correlation between loneliness and being befriended by a parent is a circumstance of extraneous variables.

As it is highly significant ( $\mathrm{r}=.007)$, it is worth noting, but the implications are unclear. Several theories in explanation of the possible causes for a significant correlation were discussed previously but was not able to be tested in this study. Further research into the types of friend requests and the dynamics of the "friend" list should be studied.

Krasnova et al. (2013) noted in their study that envy was a significant cause of loneliness in their study on Facebook and envy and added that reading the status updates, posts, and pictures increased envy as it was often viewed as a comparison. However, the data that was retrieved from this study showed no correlations between checking other's status and loneliness.

Table 18. Correlational table of viewing status updates and loneliness

\begin{tabular}{lllllll}
\hline Variable & $\begin{array}{l}\text { Pearson } \\
\text { Correlation }\end{array}$ & Sig. (2-tailed) & $\mathrm{N}$ & $\begin{array}{l}\text { Pearson } \\
\text { Correlation }\end{array}$ & $\begin{array}{l}\text { Sig. } \\
\text { (2-tailed) }\end{array}$ & $\mathrm{N}$ \\
\hline $\begin{array}{l}\text { Viewing } \\
\text { statuses }\end{array}$ & 1 & - & 243 & -.089 & .179 & 229 \\
Lonesum & -.089 & .179 & 229 & 1 & - & 307 \\
\hline
\end{tabular}

Note: *significant at the .05 level.

These tables are fairly representative of the majority of the data processed by SPSS. With only the three correlations between all of the included variables and loneliness, the results found were unexpected.

\section{Discussion}

This social networking research survey revealed very little correlations between SNS usage and loneliness. The data revealed only two significant correlations in Twitter and Pinterest. This lack of significant correlations forced us to reconsider the nature of the research. It was highly unexpected to see such stark contrast in comparison to the datasets from multiple previous SNS and loneliness studies conducted over the last several years. In addition to the majority of insignificant correlations, the significant negative correlation between loneliness and Pinterest use that indicated a decrease in loneliness was equally unexpected. The theory that was considered was in relation to the nature of the SNS platform itself, along with the users' intentions when utilizing Pinterest. However, as an SNS with less traffic, Pinterest usage had the least amount of data to be gathered, so the results may not hold true for a larger population size. Further research is required for a better understanding on this correlation.

A theorized reason for the lack of correlations in SNS and loneliness stems from geographic cultural deviance. As an island in the Pacific, the cultural diversity is wide. However, the largest portion of ethnicities are primarily local, with relatives and childhood friends nearby, decreasing the necessity of utilizing SNS for constant internet-based communications and reducing the reliance on SNS for maintaining and developing social connections. Further research will be required to understand and test the accuracy of this theory.

Another theory in explanation of these unusual results is in relation to the environmental factor of the university at which the survey was distributed. As a small university, specializing in specific fields, students and faculty 
both are familiar with each one another. In the 2018 school year, the university researched had a total student population of 1,157 undergraduates, with the ratio of student to faculty at 11:1. While numerically insignificant, other factors should be considered. On average, each department has 4-6 full-time faculty members, increasing the odds of students having the same professor multiple times. These multiple interactions increase the likelihood of familiarity and strengthens possible support channels, all of which can be correlated to a reduction in loneliness.

In comparison, a school with a similar demographic, geographic location, and cultural environment has a student-faculty ratio of 10:1. While the ratio is numerically similar, the number of students is significantly higher at 18,056 with approximately 1,800 faculty members, all which reduce the odds of repeat classes with the same faculty members. This could be a factor in regard to the lack of correlations between SNS and loneliness. Research agrees that closeness, size of community, and availability of a support structure reduces loneliness (Binder, Roberts \& Sutcliffe, 2012). These three major points are all met by the university being researched. Further research on this theory should be conducted.

Another factor, which will require further investigation, is the concept that SNS platforms consists of primarily superficial (high level) interactions. It is rare to hear about people having deep and meaningful conversations through an SNS platform. The data from this study shows that all but two of the SNS platforms analyzed (Twitter and Pinterest) had no correlation with loneliness. The irony is that our data suggests that the most popular SNS platforms, Facebook, Instagram, and SnapChat, have no relationship with a person's level of loneliness. Although these SNS platforms were designed for people to socialize, its level of interaction appears to be superficial to influence one's feelings of social connectedness to the point where it can reduce one's feelings of loneliness. This hypothesis will be investigated in a followup study.

\subsection{Conclusion}

This study was conducted on the correlations of loneliness and social networking sites (SNS). The research utilized survey-based data collected from a university student population. The outcome of this study is in contradiction to previous studies on SNS and loneliness, finding that there were minimal to no correlations between the two. Of the two significant results, hours spent on Pinterest and checking order Twitter, only the numbers from checking order Twitter fit with the results of previous studies as the correlation between hours on Pinterest and loneliness was negative, stating that there was a decrease in loneliness with an increased utilization of the platform instead of an increase in loneliness as expected.

The implications of this exploratory study are unclear, as there are extraneous factors influencing the data, including the theories on the communal environment and island mentality that is part of the university's geographical and demographical environment. While the data provides no definitive answers to the hypothesized questions, it does generate much thought into the relationship between culture, one's perception of social connectedness, and one's emotions. Further research should be conducted to account for the various confounding variables that have been theorized to affect the outcome.

\section{References}

Binder, J. F., Roberts, S. G. B., \& Sutcliffe, A. G. (2012). Closeness, loneliness, support: Core ties and significant ties in personal communities. Social Networks, 34(2), 206-214. https://doi.org/10.1016/j.socnet.2011.12.001

Boyd, D. M., \& Ellison, N. B. (2007). Social Network Sites: Definition, History, and Scholarship. Journal of computer-mediated communication. 13, 216-218. https://doi.org/10.1111/j.1083-6101.2007.00393.x

Burke, M., Marlow, C., \& Lento, T. (2010, April). Social network activity and social well-being. In Proceedings of the SIGCHI conference on human factors in computing systems, 1909-1912. https://doi.org/10.1145/1753326.1753613

Burke, M., Kraut, R., \& Marlow, C. (2011, May). Social capital on Facebook: Differentiating uses and users. In Proceedings of the SIGCHI conference on human factors in computing systems, 571-580. https://doi.org/10.1145/1978942.1979023

Krasnova, H., Wenninger, H., Widjaja, T., \& Buxmann, P. (2013). Envy on Facebook: A Hidden Threat to Users' Life Satisfaction. In 11th International Conference on Wirtschaftsinformatik.

Chang, S., Kumar, V., Gilbert, E., \& Terveen, L. (2014). Specialization, homophily, and gender in a social curation site: Findings from Pinterest. Conference on computer supported cooperative work. https://doi.org/10.1145/2531602.2531660

Cook, S. (2018, October 22). Cyberbullying around the world - which country has the most victims. 
Comparitech. Retrieved from https://www.comparitech.com/internet-providers/cyberbullying-statistics/

Deters, F. G., \& Mehl, M. R. (2013). Does posting Facebook status updates increase or decrease loneliness? An online social networking experiment. Social Psychological and Personality Science, 4(5), 579-586. https://doi.org/10.1177/1948550612469233

Festinger, L. (1954). A theory of social comparison processes. Human relations, 7, 117-140. https://doi.org/10.1177/001872675400700202

Fletcher, F., Hermida, A., Korell, D., \& Logan, D. (2012). Share, like, recommend: Decoding the social media news consumer. Journalism studies. 13(5-6), 1-8. https://doi.org/10.1080/1461670X.2012.664430

Piwek, L., \& Joinson, A. (2016). What do they say about Snapchat? Patterns of use in time-limited instant messaging service. Computers in human behavior, 54, 358-360. https://doi.org/10.1016/j.chb.2015.08.026

Keitzman, J. H., Hermkens, K., McCarthy, I. P., \& Silvestre, B. (2011). Social media? Get serious! Understanding the basic functional building blocks of social media. Business Horizons, 54, 241-242. https://doi.org/10.1016/j.bushor.2011.01.005

Khalid, C., Muscanell, N., \& Utz, S. (2015). Snapchat elicits more jealousy than Facebook: A comparison of Snapchat and Facebook use. Cyberpsychology, behavior, and social networking, 18, 141-145. https://doi.org/10.1089/cyber.2014.0479

Kwak, H., Lee, C., Park, H., \& Moon, S. (2010). What is Twitter, a Social Network or a News Media? Proceedings of the 19th international conference on World Wide Web, 591-600. https://doi.org/10.1145/1772690.1772751

Lange, P. (2008). Publicly Private and privately public: Social networking on YouTube. Journal of computer-mediated communication, 13, 361-378. https://doi.org/10.1111/j.1083-6101.2007.00400.x

Naaman, M., Boase, J., \& Lai, C. C. (2010). Is it really about me? Message content in social awareness streams. Proceedings of the 2010 ACM Conference on Computer Supported Cooperative Work. https://doi.org/10.1145/1718918.1718953

Press, G. (2018, April 8). Why Facebook triumphed over all other social networks. Forbes. Retrieved from https://www.forbes.com/sites/gilpress/2018/04/08/why-facebook-triumphed-over-all-other-social-networks/\# $2 \mathrm{~b} 17 \mathrm{c} 4 \mathrm{ed} 6 \mathrm{e} 91$

Russell, D., Peplau, L. A., \& Ferguson, M. L. (1978). Developing a measure of loneliness. Journal of Personality Assessment, 42(3), 290-294. https://doi.org/10.1207/s15327752jpa4203_11

Russell, D. (1996). UCLA Loneliness Scale (Version 3): Reliability, validity, and factor structure. Journal of Personality Assessment, 66, 20-40. https://doi.org/10.1207/s15327752jpa6601_2

Ryan's Story. (2003). Retrieved from http://ryanpatrickhalligan.org

Twitter usage statistics. (2018, November). Internet live stats. Retrieved from http://www.internetlivestats.com/twitter-statistics/

Werry, C. C. (1996). Linguistic and interactional features of Internet relay chat. In S. C. Herring (Ed.), Computer-mediated communication: Linguistic, social and cross-cultural perspectives. Amsterdam/Philadelphia: John Benjamin Publishing Company. https://doi.org/10.1075/pbns.39.06wer

Yang, C., \& Brown, B. B. (2013). Motives for Using Facebook, Patterns of Facebook Activities, and Late Adolescents' Social Adjustment to College. Journal of Youth and Adolescence, 42(3), 403-416. https://doi.org/10.1007/s10964-012-9836-x

\section{Copyrights}

Copyright for this article is retained by the author(s), with first publication rights granted to the journal.

This is an open-access article distributed under the terms and conditions of the Creative Commons Attribution license (http://creativecommons.org/licenses/by/4.0/). 